\title{
Effects of dietary soyabean, rapeseed and linseed oils on performance, slaughter yield and fatty acid profile of breast meat in turkeys*
}

\author{
J. Jankowski ${ }^{1,3}$, P. Zduńczyk², D. Mikulski ${ }^{1}$ J. Juśkiewicz², \\ M. Mikulska ${ }^{1}$ and Z. Zduńczyk ${ }^{2}$ \\ ${ }^{1}$ University of Warmia and Mazury in Olsztyn, Department of Poultry Science \\ Oczapowskiego 5, 10-718 Olsztyn, Poland \\ ${ }^{2}$ Institute of Animal Reproduction and Food Research, Polish Academy of Sciences \\ Tuwima 10, 10-747 Olsztyn, Poland
}

(Received 14 June 2011; revised version 4 November 2011; accepted 12 March 2012)

\begin{abstract}
The objective of this study was to determine the physiological effect of supplementing turkey diets with different vegetable oils, i.e. soyabean (S) oil, rapeseed (R) oil and linseed (L) oil, which have different concentrations of polyunsaturated fatty acids (PUFA). The total contents of n-6 PUFA and n-3 PUFA were as follows: diet S, 49.7 and $7.02 \%$, diet R, 33.0 and $7.96 \%$, and diet L, 30.3 and $30.6 \%$; the n-6/n-3 PUFA ratio was $7.3,4.4$ and 1.0 , respectively. The experimental materials comprised four groups of turkey hens (14 replications of fifteen birds each). The amount of dietary oil supplementation was increased from $2 \%$ in the first four weeks to $6 \%$ at the final stage of fattening (14-15 weeks). The apparent total tract digestibility of crude fat in 7-week-old turkeys ( $2.5 \%$ oil in diet) ranged from 89.9 to $91.1 \%$, and showed no statistically significant differences. Dressing percentage, breast, thigh, and drumstick muscle contents did not differ among groups. Group L had a significantly higher intestinal fat weight $(0.84 \%$ body weight $(\mathrm{BW}))$ than the other groups (0.60-0.62\%). In comparison with diet $\mathrm{S}$, diets $\mathrm{R}$ and $\mathrm{L}$ contributed to a significant decrease in the levels of saturated fatty acids (from $32.9 \%$ to 30.3 and $30.2 \%$ ) in breast meat lipids. In group L turkeys, the share of PUFA in total fatty acids in breast meat lipids was significantly higher $(37.3 \%$
\end{abstract}

\footnotetext{
* Research was realized within the project BIOFOOD - Innovative, Functional Products of Animal Origin, No. POIG.01.01.02-014-090/09 co-financed by the European Union from the European Regional Development Fund within the Innovative Economy Operational, Programme 2007-2013

${ }^{3}$ Corresponding author: e-mail: janj@uwm.edu.pl
} 
vs 29.4 and $27.1 \%$ in groups $\mathrm{S}$ and R, respectively), and the n-6/n-3 PUFA ratio was significantly lower (1.2 vs 5.6 and 5.1). As for the performance indices (final BW, feed conversion ratio), both rapeseed and linseed oils could be recognized as comparable alternatives to soyabeen oil (in both cases $\mathrm{P}>0.05$ vs $\mathrm{S}$ group). However, the highest final BW followed the dietary treatment with linseed oil $(\mathrm{P}<0.05$ vs group $\mathrm{R})$.

KEY WORDS: soyabean oil, rapeseed oil, linseed oil, fatty acid, growth performance, slaughter yield, turkey

\section{INTRODUCTION}

The results of previous studies confirm that the consumption of polyunsaturated fatty acids (PUFA), particularly n-3 fatty acids, plays an important role in coronary heart disease prevention (Harris et al., 2007). Nutritionally important n-3 fatty acids include eicosapentaenoic acid (EPA; C20:5n-3), docosahexaenoic acid (DHA; C22:6n-3), which are found in fish oils, and $\alpha$-linolenic acid (ALA; C18:3n3), which can be found in many vegetable oils, including linseed oil (Kavouridou et al., 2008).

The last two decades have witnessed growing interest in linseed and linseed oil, believed to enhance the health-promoting properties of animal products, including poultry meat. It was found that the inclusion of linseed in livestock diets induced significant modifications of human plasma and erythrocyte fatty acid composition (comparable to that noted under the 'Cretan' diet) and a sharp increase in CLA (Weill et al., 2002). Feeding chickens a diet containing $12 \%$ linseed increases fatty acid deposition in broiler meat. Thus, consuming $100 \mathrm{~g}$ of such fatty acid-enriched meat from legs or wings, approximately $2 \mathrm{~g}$ of $\mathrm{n}-3$ fatty acids would be provided by each portion, which offers consumers an alternative to enhance their daily $n-3$ fatty acid intake (Jia et al., 2010).

To date, the experiments indicating that linseed is a good candidate for enriching poultry meat with n-3 fatty acids have been conducted mostly on broilers, and the number of experiments performed on fast-growing turkeys is much smaller (Nguyen et al., 2003; Has-Schön et al., 2008). Earlier comparative studies with young birds have shown a difference in fat utilization between chickens and young turkeys (Mossab et al., 2000). Therefore, the results obtained for chickens may be extrapolated to turkeys to a limited extent only. The dietary inclusion of PUFA-rich oils in the nutritional regime of young turkeys is further justified by the fact that fattening lasts long (min. 15 weeks) and the incidence of spontaneous cardiomyopathy is relatively high in this species (Mikulski et al., 2009). 
The objective of this study was to determine the physiological effect of supplementing turkey diets with different vegetable oils, i.e. linseed oil, with a low n-6/n-3 fatty acid ratio, rapeseed and soyabean oils, having moderate and high $n-6 / n-3$ fatty acid ratios, respectively.

\section{MATERIAL AND METHODS}

\section{Birds and housing}

The experiment was carried out at the Research Laboratory of the Department of Poultry Science, University of Warmia and Mazury in Olsztyn, according to the guidelines of the Local Animal Experimentation Ethics Committee.

A total of 630 one-day-old heavy-type BIG-6 turkey females, sexed at the local commercial hatchery, were randomly assigned to three feeding groups (14 replications). The birds were kept in pens (15 turkeys per pen, $4 \mathrm{~m}^{2}$ ) on litter in a building with a controlled environment. The temperature and lighting programme were consistent with the recommendations of the Aviagen Inc. (2007). The birds had free access to feed and water. The trial was conducted to 105 days of age.

\section{Diets}

Turkeys were fed three diets differing in the type of vegetable oil added: soyabean (S) oil, rapeseed (R) oil and linseed (L) oil. Feed grade soyabean oil was purchased from Toepfer International Poland, rapeseed oil was purchased from the Kruszwica S.A. vegetable oil processing plant (Poland), and linseed oil, from a vegetable oil pressing plant in Grodzisk Wielkopolski (Poland). The oils were added to isoenergetic and isointrogenous diets (Table 1). The four-phase feeding programme applied in the study followed commercial recommendations. All diets were offered ad libitum as mashes without any feed additives.

\section{Growth trial}

Experimental diets (Table 1) were offered ad libitum as mashes. At the end of each period, on days 28, 63, 91 and 105 of the experiment, the birds were weighed and feed intake was recorded. Feed utilization efficiency was calculated for each period. Mortality was recorded daily, and the weights of dead birds were used to adjust average daily gain, average daily feed intake, and feed conversion ratio (FCR). 
Table 1. Composition and calculated nutrient content of diets with different vegetable oils, soyabean oil (S), rapeseed oil (R) and linseed oil (L)

\begin{tabular}{|c|c|c|c|c|}
\hline \multirow{2}{*}{ Item } & \multicolumn{4}{|c|}{ Feeding phase, weeks } \\
\hline & $1-4$ & $5-9$ & $10-13$ & $14-15$ \\
\hline \multicolumn{5}{|l|}{ Ingredients, \% } \\
\hline wheat & 26.44 & 31.66 & $35.88(35.48)^{1}$ & $43.60(43.18)^{1}$ \\
\hline maize & 20.00 & 20.00 & 20.00 & 20.00 \\
\hline soyabean meal & 39.00 & 35.66 & $32.60(32.70)^{1}$ & $24.60(24.67)^{1}$ \\
\hline rapeseed meal & 3.00 & 3.00 & 3.00 & 3.00 \\
\hline potato protein & 5.00 & 3.00 & - & - \\
\hline vegetable oil: $\mathrm{S}, \mathrm{R}$ or $\mathrm{L}$ & 2.00 & 2.50 & $4.70(5.00)^{1}$ & $5.40(5.75)^{1}$ \\
\hline sodium bicarbonate & 0.10 & 0.10 & 0.10 & 0.10 \\
\hline sodium chloride & 0.20 & 0.20 & 0.18 & 0.16 \\
\hline limestone & 1.70 & 1.70 & 1.49 & 1.46 \\
\hline monocalcium phosphate & 1.50 & 1.10 & 0.88 & 0.77 \\
\hline DL-methionine & 0.30 & 0.33 & 0.33 & 0.27 \\
\hline L-lysine- $\mathrm{HCl}$ & 0.35 & 0.35 & 0.36 & 0.27 \\
\hline L-threonine & 0.09 & 0.08 & 0.16 & 0.05 \\
\hline choline chloride & 0.07 & 0.07 & 0.07 & 0.07 \\
\hline vitamin-mineral premix ${ }^{2}$ & 0.25 & 0.25 & 0.25 & 0.25 \\
\hline \multicolumn{5}{|l|}{ Calculated nutrient content } \\
\hline $\mathrm{ME}, \mathrm{kcal} / \mathrm{kg}$ & 2788 & 2852 & 3010 & 3110 \\
\hline crude protein, $\%$ & 28.01 & 25.61 & 22.51 & 19.76 \\
\hline lysine, \% & 1.79 & 1.61 & 1.39 & 1.12 \\
\hline methionine + cystine, $\%$ & 1.17 & 1.13 & 1.04 & 0.91 \\
\hline $\mathrm{Ca}, \%$ & 1.06 & 0.98 & 0.85 & 0.80 \\
\hline available P, \% & 0.48 & 0.40 & 0.35 & 0.33 \\
\hline $\mathrm{Na}, \%$ & 0.13 & 0.13 & 0.12 & 0.11 \\
\hline
\end{tabular}

${ }^{1}$ in weeks 10-13 and 14-15, the amount of rapeseed oil was increased due to its lower energy value, adjusting the content of wheat and soyabean meal in the diet (the adjusted values are given in brackets)

2 vitamin and mineral premix supplied per kg of diet: IU: vit. A 15 000, vit. $\mathrm{D}_{3} 3000$; mg: vit. E 54, vit. $K_{3} 3$, vit. $B_{1} 3.5$, vit. $B_{2} 10$, vit. $B_{6} 6$, vit. $B_{12} 0.03$, folic acid 2, calcium-D-pantothenate 15 , niacin 75, biotin 0.36, choline 600, Se 0.3, Zn 90, Cu 10, Fe 60, Mn 150, I 1.0

\section{Balance trial}

After 8 weeks of feeding, 14 birds were selected randomly from each treatment (7 replications, 2 birds each) and transferred to battery cages for balance trials. Cages were thermostatically controlled, and turkeys had free access to water from nipple drinkers. The birds received ad libitum a diet administered in the second phase (from week 5 to 9) of feeding. All diets contained $\mathrm{TiO}_{2}$ at a rate $5 \mathrm{~g} / \mathrm{kg}$ as an indigestible dietary marker for the calculation of nutrient digestibility coefficients. After a two-day preliminary period, a collection period was continued for five days, the excreta were collected daily, freeze-dried and ground through a $0.5 \mathrm{~mm}$ screen. 


\section{Sample collection}

After 15 weeks of feeding, blood samples $(10 \mathrm{ml})$ were collected from the wing vein of eight turkeys from each group to measure the levels of glucose, urea, triglycerides, total and HDL cholesterol. Eight birds representing the average body weight of each group ( 24 birds in total) were sacrificed by cervical dislocation, scalded, defeathered and eviscerated. Following evisceration, whole carcasses were air prechilled at $12^{\circ} \mathrm{C}$ for $30 \mathrm{~min}$, air chilled and stored at $4^{\circ} \mathrm{C}$, and then hand-deboned on a cone $24 \mathrm{~h}$ post-mortem. The carcass, intestinal and abdominal fat, breast meat (including pectoralis major and pectoralis minor muscles) and leg meat (including thigh and drumstick) were weighed. The percentage of eviscerated carcass was calculated as the ratio between the eviscerated carcass and live body weight (LBW) after fasting. The weights of the breast meat, leg meat, intestinal and abdominal fat were also calculated in relation to LBW. The left pectoralis major subsamples were vacuum-packaged and frozen at $-20^{\circ} \mathrm{C}$ (3 days) for fatty acid profile analysis.

\section{Analysis}

Samples of feed and dried excreta were analysed in triplicate for dry matter, crude fat, nitrogen, crude ash (methods 934.01, 920.39, 954.01, 942.05, respectively; AOAC, 2005). Ti was determined by optical emission spectrometry with excitation in inductively coupled plasma (ICP-OES) using an Ultima 2 sequence camera with vertical plasma from Horiba Jobin Yvon (procedure developed in the GBC Poland, Laboratory, Niezdrowice).

The gross energy value (GE) of feed and excreta was determined with the use of a Parr adiabatic oxygen bomb calorimeter (KL-10, Precyzja, Bydgoszcz, Poland). The apparent total tract digestibility and retention coefficients (ADC) of dry matter $(\mathrm{DM})$, nitrogen $(\mathrm{N})$, crude fat $(\mathrm{CF})$ were calculated based on the equation developed by Ravindran et al. (1999).

Blood serum parameters were determined using the Cobas Integra 400 system (Modular Analytics, Roche), as follows: glucose, by an enzymatic method with the use of hexokinase; urea, by a kinetic method with the use of urease; glutamate dehydrogenase, triglycerides, total cholesterol and HDL cholesterol, by enzymatic-colorimetric methods.

Fat was separated via extraction of minced meat with a chloroform and methanol mixture $(2: 1 \mathrm{v}: \mathrm{v})$, and then the fatty acids were methylated with a mixture of chloroform, methanol and sulphuric acid (100:100:1 v:v) according to the Peisker's method (Peisker, 1964). The samples were subjected to chromatographic analysis to determine fatty acid composition. A $6890 \mathrm{~N}$ gas chromatograph (Agilent Technologies Inc. Palo Alto, USA) equipped with a flame ionization detector 
(FID) was used. Column (capillary, $0.32 \mathrm{~mm} \times 30 \mathrm{~m}$ ), injector, and detector temperatures were 180,225 and $250^{\circ} \mathrm{C}$, respectively. The flow rate of helium carrier gas was $0.7 \mathrm{~cm}^{3} / \mathrm{min}$. Fatty acids were identified based on their retention times and were expressed as a percentage of the sum of identified fatty acids (\% $\mathrm{wt} / \mathrm{wt}$ ). All analyses were performed in duplicate. The concentrations of saturated fatty acids (SFA), monounsaturated fatty acids (MUFA) and polyunsaturated fatty acids (PUFA) were calculated.

\section{Statistical analysis}

For performance parameters, a pen was considered to be a replicate experimental unit for the statistical analysis. Other results were analysed with each turkey as a replicate. The model assumptions of normality and homogeneity of treatment variance were examined by the Shapiro-Wilk test and Levene's test, respectively. All percentage data (e.g., mortality, digestibility coefficients, carcass traits and fatty acids profile) were transformed using Bliss degrees. The results presented in this paper are from the untransformed data.

When a measurement variable held the normality assumption of an ANOVA, the data were analysed using the General Linear Models (GLM) procedure for ANOVA of Statistica 8.0 software (StatSoft Inc., 2007) according to the following model:

$$
\mathrm{y}_{\mathrm{ij}}=\mu+\alpha_{\mathrm{i}}+\mathrm{e}_{\mathrm{ij}}
$$

where: $y_{i j}$ - the observed dependent variable, $\mu$ - the overall mean, $\alpha_{i}$ - the fixed effect of $i$-th treatment $(i=1,2,3), e_{i j}$ - the random error connected with $i j$-th observation.

When a significant treatment effect was noted, the post-hoc Newman-Keuls test was used to determine differences between treatment groups. The KruskalWallis ANOVA procedure on ranks was used when the measurement variable did not hold the normality assumption of the ANOVA (e.g., C16:0, C17:0, C18:0 and $\mathrm{C} 18: 2 \mathrm{n}-6$ fatty acid). Treatment effects were considered to be significant at $\mathrm{P} \leq 0.05$. All data were expressed as mean values with pooled standard errors.

\section{RESULTS}

The experimental diets differed with regard to their fatty acid profiles. Diet $\mathrm{S}$ had higher concentrations of palmitic, stearic and linoleic acids, diet $\mathrm{R}$ had a higher oleic acid content, whereas diet L, higher levels of linolenic acid (Table 2). Diets $S$ and $L$ were characterized by the highest concentrations of n-6 PUFA and n-3 PUFA, respectively. The n-6/n-3 PUFA ratio varied, reaching 7.31 in the $S$ diet, 4.33 in the $\mathrm{R}$ diet, and 1.03 in the $\mathrm{L}$ diet. 
Table 2. Fatty acid profile of diets supplemented with different vegetable oils (mean values of fours diets fed to turkeys at different ages)

\begin{tabular}{lccc}
\hline Fatty acid & \multicolumn{3}{c}{ Experimental group $^{1}$} \\
\cline { 2 - 4 } C14 :0 & $\mathrm{S}$ & $\mathrm{R}$ & $\mathrm{L}$ \\
C15 :0 & 0.20 & 0.26 & 0.35 \\
C16:0 & 0.04 & 0.04 & 0.05 \\
C16:1 & 12.6 & 9.88 & 10.1 \\
C17 :0 & 0.26 & 0.25 & 0.24 \\
C17:1 & 0.11 & 0.09 & 0.10 \\
C18:0 & 0.06 & 0.06 & 0.06 \\
C 18:1 cis 9 & 3.62 & 2.80 & 3.86 \\
C 18:1 cis 11 & 23.1 & 41.4 & 21.7 \\
C18:2n-6 & 1.71 & 2.10 & 1.43 \\
C18:3n-3 & 49.7 & 33.0 & 30.3 \\
C20:0 & 7.02 & 7.96 & 30.6 \\
C20:1 & 0.48 & 0.52 & 0.41 \\
C22:0 & 0.68 & 1.02 & 0.42 \\
C22:1 & 0.38 & 0.30 & 0.24 \\
SFA & 0.00 & 0.29 & 0.00 \\
MUFA & & & 15.1 \\
PUFA & 17.4 & 13.9 & 24.0 \\
n-6 PUFA & 25.8 & 45.2 & 60.9 \\
n-3 PUFA & 56.8 & 40.9 & 30.3 \\
n-6/n-3 PUFA & 49.7 & 33.0 & 30.6 \\
\hline S - & 7.02 & 7.96 & 1.0 \\
\hline
\end{tabular}

${ }^{1} \mathrm{~S}$ - soyabean oil, R - rapeseed oil, L - linseed oil

The total tract apparent digestibility of dry matter and crude fat, apparent nitrogen retention, and gross energy metabolizability were similar in all groups, regardless of the type of dietary oil (Table 3 ).

Table 3. The effect of different oils contained in diets on apparent nutrient digestibility and nitrogen retention in turkeys at 7 weeks of age, $\%^{1}$

\begin{tabular}{lccccc}
\hline Item & \multicolumn{3}{c}{ Treatment $^{2}$} & \multirow{2}{*}{ SEM $^{3}$} & \multirow{2}{*}{$\mathrm{P}$} \\
\cline { 2 - 4 } Coefficient digestibility & $\mathrm{S}$ & $\mathrm{R}$ & $\mathrm{L}$ & & \\
$\quad$ & & & & & \\
$\quad$ dry matter & 61.2 & 60.9 & 61.0 & 0.567 & 0.971 \\
$\quad$ crude fat & 91.1 & 90.9 & 89.9 & 0.528 & 0.408 \\
Nitrogen retention & 51.7 & 51.3 & 52.3 & 0.957 & 0.927 \\
GE metabolizability & 68.1 & 68.3 & 68.9 & 0.501 & 0.585 \\
\hline
\end{tabular}

${ }^{1}$ data represent mean values of 7 samples per treatment; ${ }^{2}$ as in Table $2 ;{ }^{3}$ SEM - standard error of the mean (SD for all birds divided by the square root of turkey number)

No significant differences were found between the groups in the values of blood biochemical parameters, i.e. glucose, urea, triglycerides, total cholesterol and HDL cholesterol (Table 4). 
Table 4. The values of selected blood parameters of turkeys at 15 weeks of age, $\mathrm{mg} / \mathrm{dl}^{1}$

\begin{tabular}{lccccc}
\hline \multirow{2}{*}{ Parameter } & \multicolumn{3}{c}{ Treatment $^{2}$} & \multirow{2}{*}{ SEM $^{3}$} & \multirow{2}{*}{$\mathrm{P}$} \\
\cline { 2 - 4 } Glucose & $\mathrm{S}$ & $\mathrm{R}$ & $\mathrm{L}$ & & \\
Urea & 266 & 269 & 264 & 362 & 0.897 \\
Triglyceride & 1.1 & 1.4 & 1.5 & 0.098 & 0.284 \\
Total cholesterol & 64 & 84 & 63 & 8.093 & 0.523 \\
HDL cholesterol & 128 & 123 & 115 & 2.881 & 0.179 \\
\hline
\end{tabular}

${ }^{1}$ data represent mean values of 7 samples per treatment; ${ }^{2}$ as in Table $2 ;{ }^{3}$ SEM - standard error of the mean (SD for all birds divided by the square root of turkey number)

The mortality rates of turkeys at successive stages of feeding were low, ranging from 2.1 to $3.5 \%$ over the entire experimental period, and differences between the groups were statistically non-significant (Table 5). There were no significant differences in the body weights of turkeys until $63 \mathrm{~d}$ of age. At the age of 91 and $105 \mathrm{~d}$, the highest and the lowest body weights were noted in groups $\mathrm{L}$ and $\mathrm{R}$, respectively $(\mathrm{P}<0.05)$, but no significant differences were found between those two groups and group S. Average FCR values were comparable at successive stages of feeding and over the entire experimental period, irrespective of the type of dietary oil.

Table 5. Growth performance of female turkeys fed diets with different oils ${ }^{1}$

\begin{tabular}{|c|c|c|c|c|c|}
\hline \multirow{2}{*}{ Item } & \multicolumn{3}{|c|}{ Treatment $^{2}$} & \multirow{2}{*}{$\mathrm{SEM}^{3}$} & \multirow{2}{*}{$\mathrm{P}$} \\
\hline & $\mathrm{S}$ & $\mathrm{R}$ & $\mathrm{L}$ & & \\
\hline \multicolumn{6}{|l|}{ Mortality, $\%$} \\
\hline 1-28 days & 0.99 & 0.30 & 0.89 & 0.257 & 0.512 \\
\hline 1-63 days & 0.99 & 0.60 & 0.89 & 0.272 & 0.839 \\
\hline $1-105$ days & 1.32 & 0.60 & 1.77 & 0.319 & 0.330 \\
\hline \multicolumn{6}{|l|}{ Body weight, $\mathrm{kg}$} \\
\hline 28 days & 0.83 & 0.83 & 0.84 & 0.005 & 0.450 \\
\hline 63 days & 4.17 & 4.13 & 4.22 & 0.018 & 0.148 \\
\hline 91 days & $7.66^{\mathrm{ab}}$ & $7.57^{b}$ & $7.77^{\mathrm{a}}$ & 0.032 & 0.022 \\
\hline 105 days & $9.35^{\mathrm{ab}}$ & $9.22^{\mathrm{b}}$ & $9.41^{\mathrm{a}}$ & 0.030 & 0.025 \\
\hline \multicolumn{6}{|c|}{ Feed conversion ratio, $\mathrm{kg}$ feed $/ \mathrm{kg} B W G$} \\
\hline 1-28 days & 1.52 & 1.50 & 1.52 & 0.009 & 0.389 \\
\hline 1-63 days & 2.01 & 2.01 & 1.99 & 0.006 & 0.312 \\
\hline 1-91 days & 2.34 & 2.36 & 2.33 & 0.009 & 0.345 \\
\hline 1-105 days & 2.57 & 2.60 & 2.58 & 0.009 & 0.181 \\
\hline
\end{tabular}

No significant differences were observed in carcass dressing percentage, the content of major muscle groups or abdominal fat in turkey carcasses (Table 6). Intestinal fat content was significantly $(\mathrm{P}=0.045)$ higher in group $\mathrm{L}$ than in the remaining two. 
Table 6 . Carcass characteristic of turkeys at 15 weeks of age, $\%$ of body weight ${ }^{1}$

\begin{tabular}{|c|c|c|c|c|c|}
\hline \multirow[b]{2}{*}{ Item } & \multicolumn{3}{|c|}{ Treatment $^{2}$} & \multirow{2}{*}{$\mathrm{SEM}^{3}$} & \multirow[b]{2}{*}{$\mathrm{P}$} \\
\hline & $\mathrm{S}$ & $\mathrm{R}$ & $\mathrm{L}$ & & \\
\hline Dressing percentage & 81.9 & 81.6 & 81.7 & 0.221 & 0.803 \\
\hline Breast muscles & 22.7 & 22.4 & 22.1 & 0.208 & 0.531 \\
\hline Thigh muscles & 11.7 & 11.1 & 11.2 & 0.137 & 0.163 \\
\hline Drumstick muscles & 8.2 & 8.3 & 8.1 & 0.113 & 0.771 \\
\hline Intestinal fat & $0.60^{\mathrm{a}}$ & $0.62^{\mathrm{a}}$ & $0.84^{\mathrm{b}}$ & 0.046 & 0.045 \\
\hline Abdominal fat & 0.82 & 0.91 & 0.89 & 0.054 & 0.785 \\
\hline
\end{tabular}

1 data represent mean values of 7 samples per treatment; ${ }^{2}$ as in Table $2 ;{ }^{3} \mathrm{SEM}$ - standard error of the mean (SD for all birds divided by the square root of turkey number); ${ }^{\mathrm{a}, \mathrm{b}}$ means within the same line with no common superscripts differ at $\mathrm{P}<0.05$

The composition of experimental diets affected the fatty acid profile of breast muscle lipids (Table 7). In quantitative terms, the differences in the concentrations of the most important fatty acids between the experimental groups were as follows:

Table 7. The effect of different oils contained in diets on the fatty acids profile of breast meat in turkeys at 15 weeks of age, percentage content in total fatty acids ${ }^{1}$

\begin{tabular}{|c|c|c|c|c|c|}
\hline \multirow{2}{*}{ Fatty acid } & \multicolumn{3}{|c|}{ Treatment $^{2}$} & \multirow{2}{*}{ SEM $^{3}$} & \multirow[b]{2}{*}{$\mathrm{P}$} \\
\hline & $\mathrm{S}$ & $\mathrm{R}$ & $\mathrm{L}$ & & \\
\hline $\bar{C} 14: 0$ & $0.55^{\mathrm{b}}$ & $0.65^{\mathrm{a}}$ & $0.60^{\mathrm{ab}}$ & 0.015 & 0.018 \\
\hline C14:1 & 0.13 & 0.15 & 0.14 & 0.008 & 0.802 \\
\hline C15:0 & 0.14 & 0.13 & 0.15 & 0.004 & 0.233 \\
\hline C16:0 & $22.2^{\mathrm{a}}$ & $21.1^{\mathrm{b}}$ & $20.9^{\mathrm{b}}$ & 0.181 & 0.006 \\
\hline C16:1 & 3.17 & 3.69 & 3.69 & 0.213 & 0.536 \\
\hline C17:0 & 0.18 & 0.17 & 0.18 & 0.005 & 0.337 \\
\hline C17:1 & 0.11 & 0.13 & 0.12 & 0.004 & 0.387 \\
\hline C18:0 & $9.18^{\mathrm{a}}$ & $8.09^{\mathrm{b}}$ & $8.23^{\mathrm{b}}$ & 0.192 & 0.042 \\
\hline C18:1 CIS9 & $30.7^{\mathrm{b}}$ & $35.2^{\mathrm{a}}$ & $26.6^{\mathrm{c}}$ & 0.940 & $<0.001$ \\
\hline C18:1 CIS11 & $2.49^{\mathrm{a}}$ & $2.76^{\mathrm{a}}$ & $1.63^{\mathrm{b}}$ & 0.135 & $<0.001$ \\
\hline Total C18:1 & $33.7^{\mathrm{b}}$ & $38.0^{\mathrm{a}}$ & $28.3^{\mathrm{c}}$ & 1.049 & $<0.001$ \\
\hline C18:2 & $22.01^{\mathrm{a}}$ & $20.6^{\mathrm{ab}}$ & $19.7^{\mathrm{b}}$ & 0.415 & 0.039 \\
\hline C18:3 & $3.79^{\mathrm{b}}$ & $3.91^{\mathrm{b}}$ & $15.58^{\mathrm{a}}$ & 1.410 & $<0.001$ \\
\hline C20:0 & $0.15^{\mathrm{a}}$ & $0.15^{\mathrm{a}}$ & $0.13^{\mathrm{b}}$ & 0.004 & 0.003 \\
\hline C20:1 & $0.45^{\mathrm{b}}$ & $0.61^{\mathrm{a}}$ & $0.27^{\mathrm{c}}$ & 0.037 & $<0.001$ \\
\hline C20:2 & $0.28^{\mathrm{a}}$ & $0.24^{\mathrm{ab}}$ & $0.20^{\mathrm{b}}$ & 0.015 & 0.042 \\
\hline C20:4 & $2.47^{\mathrm{a}}$ & $1.94^{\mathrm{b}}$ & $0.93^{b}$ & 0.216 & 0.003 \\
\hline C20:5 & $0.31^{\mathrm{b}}$ & $0.25^{\mathrm{b}}$ & $0.63^{\mathrm{a}}$ & 0.049 & $<0.001$ \\
\hline $\mathrm{C} 22: 6$ & 0.27 & 0.23 & 0.26 & 0.021 & 0.734 \\
\hline SFA & $32.9^{\mathrm{a}}$ & $30.3^{\mathrm{b}}$ & $30.2^{\mathrm{b}}$ & 0.401 & $<0.001$ \\
\hline MUFA & $37.6^{\mathrm{b}}$ & $42.5^{\mathrm{a}}$ & $32.5^{\mathrm{c}}$ & 1.151 & $<0.001$ \\
\hline PUFA & $29.4^{\mathrm{b}}$ & $27.1^{\mathrm{b}}$ & $37.3^{\mathrm{a}}$ & 1.185 & $<0.001$ \\
\hline n-6 PUFA & $24.5^{\mathrm{a}}$ & $22.5^{\mathrm{b}}$ & $20.7^{\mathrm{b}}$ & 0.564 & 0.002 \\
\hline n-3 PUFA & $4.39^{\mathrm{b}}$ & $4.39^{\mathrm{b}}$ & $16.5^{\mathrm{a}}$ & 1.453 & $<0.001$ \\
\hline n-6/n-3 PUFA ${ }^{4}$ & $5.61^{\mathrm{a}}$ & $5.13^{\mathrm{a}}$ & $1.25^{\mathrm{b}}$ & 0.518 & $<0.001$ \\
\hline
\end{tabular}

${ }_{1}^{1}$ data represent mean values of 7 samples per treatment; ${ }^{2}$ as in Table $2 ;{ }^{3} \mathrm{SEM}$ - standard error of the mean (SD for all birds divided by the square root of turkey number); ${ }^{\mathrm{a}, \mathrm{b}}$ means within the same line with no common superscripts differ at $\mathrm{P}<0.05$; SFA - saturated fatty acids; MUFA - monounsaturated fatty acids; PUFA - polyunsaturated fatty acids; ${ }^{4} n-6 / n-3$ PUFA $=$ ratio of n-6 FA (C18:2 + C20:4) to n-3 FA (C18:3 + C20:5 + C22:6) 
palmitic acid: $\mathrm{S}>\mathrm{R}$ and $\mathrm{L}(\mathrm{P}=0.006)$, stearic acid: $\mathrm{S}>\mathrm{R}$ and $\mathrm{L}(\mathrm{P}=0.042)$, oleic acid: $\mathrm{R}>\mathrm{S}>\mathrm{L}(\mathrm{P}<0.001)$, linolenic acid: $\mathrm{L}>\mathrm{S}$ and $\mathrm{R}(\mathrm{P}<0.001)$, arachidonic acid (AA): $\mathrm{S}>\mathrm{R}, \mathrm{L}(\mathrm{P}=0.003)$ as well as eicosapentaenoic (EPA) acid: $\mathrm{L}>\mathrm{S}$ and $\mathrm{R}(\mathrm{P}<0.001)$. The experimental treatments did not change the docosahexaenoic (DHA) acid content. In comparison with group S, the share of SFA was lower and the share of UFA was higher in groups $\mathrm{R}$ and $\mathrm{L}$ in the total fatty acid pool (both $\mathrm{P}<0.001)$. As regards the share of selected fatty acids, the differences between the experimental groups were as follows: MUFA: $\mathrm{R}>\mathrm{S}>\mathrm{L}(\mathrm{P}<0.001)$, PUFA: $\mathrm{S}$ and $\mathrm{R}<\mathrm{L}(\mathrm{P}<0.001), \mathrm{n}-6$ PUFA: $\mathrm{S}>\mathrm{R}$ and $\mathrm{L}(\mathrm{P}<0.001)$, n-3 PUFA: $\mathrm{S}$ and $\mathrm{R}<\mathrm{L}$ $(\mathrm{P}<0.001)$, the $\mathrm{n}-6 / \mathrm{n}-3$ fatty acid ratio: $\mathrm{S}$ and $\mathrm{R}<\mathrm{L}(\mathrm{P}<0.001)$.

\section{DISCUSSION}

The experimental diets differed with regard to their fatty acid profiles. The diet with soyabean oil had higher concentrations of palmitic, stearic and linoleic acids, the diet with rapeseed oil had a higher oleic acid content, the one with linseed oil had higher levels of linolenic acid. The diets with soyabean oil and linseed oil were characterized by the highest share of n-6 PUFA and n-3 PUFA in the total fatty acid pool, respectively. As a result, the n-6/n-3 PUFA ratio reached the highest value in the diet with soyabean oil, followed by the diet with rapeseed oil and that with linseed oil. The differences in the fatty acid profile of experimental diets resulted from the composition of vegetable oils, including a relatively high content of palmitic and oleic acids, an even higher content of linoleic acid and a low content of linolenic acid in soyabean oil (Crespo and Esteve-Garcia, 2002; Kavouridou et al., 2008), high linolenic acid and very high oleic acid contents of rapeseed oil, and a low (similarly as in soyabean oil) linolenic acid content (Zanini et al., 2006). Linseed oil, compared with soyabean oil, contains substantially less linoleic acid and significantly more linolenic acid (Crespo and Esteve-Garcia, 2002; Kavouridou et al., 2008). Rapeseed oil, in comparison with linseed oil, has a similar linoleic acid content and a much lower linolenic acid content (Nguyen et al., 2003).

The differences in the fatty acid profiles of diets had no effect on the digestibility coefficients of dry matter and crude fat, the coefficient of apparent nitrogen retention and the coefficient of gross energy metabolizability in six-week-old turkeys. In young turkeys, similarly as in chickens, fatty acid digestibility decreases proportionally to chain length, and increases along with an increase in the number of unsaturated bonds (Mossab et al., 2000). Thus, the digestibility of vegetable oils may be higher than of animal fats (Mossab et al., 2000), and differences in the digestibility of various vegetable oils remain small 
(Nguyen et al., 2003). The coefficients of crude fat digestibility and nitrogen retention may be similar, even at a high (10\%) content of soyabean and linseed oils in broiler chicken diets (Kavouridou et al., 2008).

In the present study, no significant differences were found between the groups of turkeys with respect to the blood levels of glucose, urea, triglycerides, total and HDL cholesterol. Similar results were reported for chickens fed diets supplemented with soyabean oil or linseed oil (Febel et al., 2008). In another experiment, lower plasma cholesterol levels were noted in broilers fed diets with sunflower oil or linseed oil, as compared with birds fed tallow or olive oil (Crespo and Esteve-Garcia, 2002). The data obtained by other authors (Jurgonski et al., 2008) suggest that the type of dietary fat can influence glucose metabolism and its transmission from plasma to tissue. No differences in serum glucose levels were observed between the experimental groups in our study.

Previous research shows that the lipid profile of dietary fat has no effect on body weight gains in broiler chickens. Such results were reported for chickens fed diets supplemented with fish oil and rapeseed oil (Lopez-Ferrer et al., 1999), rapeseed oil or linseed oil (Nguyen et al., 2003) and a combination of various vegetable oils, including soyabean oil and linseed oil (Kavouridou et al., 2008). The final body weights of turkeys were also similar if their diets contained tallow, olive, sunflower oil or linseed oil (Crespo and Esteve-Garcia, 2002), as well as soyabean oil, fish oil or linseed oil (Delezie et al., 2010). In our experiment, the substitution of rapeseed oil for soyabean oil had no influence on feed conversion and the final body weights of birds, but turkeys fed linseed oil were heavier than those fed rapeseed oil.

No significant differences were observed in carcass dressing percentage and the content of major muscle groups and abdominal fat in turkey carcasses. Intestinal fat content was significantly $(\mathrm{P}=0.045)$ higher in turkeys fed a diet with linseed oil than in the other two groups. This is difficult to explain, especially that no experiments of this type have been conducted on turkeys to date. Replacement of soyabean oil with linseed oil in chicken diets had no effect on abdominal fat (Crespo and Esteve-Garcia, 2002), and the fat content of breast muscles was higher when rapeseed oil was substituted for soyabean oil (Zanini et al., 2006), while it remained on a similar level in birds fed diets supplemented with canola seed and linseed (Rahimi et al., 2011).

In the present study, rapeseed oil used as a substitute for soyabean oil contributed to a significant increase in the total pool of unsaturated fatty acids (UFA) in breast muscle lipids, mostly due to an increase in the concentrations of monounsaturated $\mathrm{C} 18$ fatty acids (oleic and elaidic). As a result, total PUFA levels were significantly lower, and a decrease in the share of n-6 PUFA insignificantly improved the n-6/n-3 PUFA ratio, compared with turkeys receiving soyabean oil. 
The changes in the fatty acid profile noted in our experiment correspond to those observed in birds fed rapeseed oil-supplemented diets (Has-Schön et al., 2008). In comparison with the cited studies, in our experiment the share of total PUFAs was lower and the n-6/n-3 PUFA ratio was similar (above 5). With regard to numerous indicators, including the concentrations of MUFA and n-6 and n-3 PUFA, our results are consistent with the findings reported for broilers fed diets supplemented with rapeseed oil by Lopez-Ferrer et al. (1999).

In the present experiment, the replacement of soyabean oil with linseed oil in turkey diets led to a significant decrease in MUFA levels and an increase in total PUFA concentrations, including a nearly four-fold increase in the share of n-3 PUFA in breast muscle lipids. As a result, the n-6/n-3 PUFA ratio decreased from 5.6 to 1.2 , compared with 5.1 in the meat of turkeys fed soyabean oil. The changes in the fatty acid profile, noted in our experiment, correspond to those observed in birds fed rapeseed oil-supplemented diets and in turkeys (Has-Schön et al., 2008). In comparison with the cited studies, in our experiment the share of total PUFA was lower and the n-6/n-3 PUFA ratio was similar (above 5). With regard to numerous indicators, including the concentrations of MUFA and n- 6 and n-3 PUFA, our results are consistent with the findings reported for broilers fed diets supplemented with rapeseed oil by Lopez-Ferrer et al. (1999).

In other experiments involving chickens (Febel et al., 2008) and turkeys (Delezie et al., 2010), differences in the n-6/n-3 PUFA ratio between birds fed diets supplemented with soyabean oil and linseed oil were even higher, reaching 8.1:1.9 and 9.6:1.7, respectively. In the above studies, despite considerable differences in the fatty acid profile of vegetable oils, the differences in the concentrations of major fatty acid groups, i.e. SFA, UFA and PUFA, were smaller than those noted in our experiment. In a study by Rahimi et al. (2011), diet supplementation with linseed and canola seed led to significant differences in the share of MUFA (22.8 and 56.6, respectively) and PUFA (66.6 and 35.6, respectively) in the fatty acid profile of diets, but it had a much weaker effect on the fatty acid composition of breast muscles. Our results support the findings of other authors (Lopez-Ferrer et al., 1999; Crespo and Esteve-Garcia, 2002; Nguyen et al., 2003) who demonstrated that linseed oil (or linseed) is a valuable source of n-3 PUFA that can be effectively transferred from feed to carcass lipids.

\section{CONCLUSIONS}

It may be concluded that the replacement of soyabean oil with rapeseed oil in turkey diets allows maintaining comparable growth performance, with no 
significant improvement in the fatty acid profile of turkey meat. Rapeseed oil contributes to an increase in the share of UFA in the total fatty acid pool, but this concerns primarily oleic acid. Linseed oil, used as an alternative to rapeseed oil, has no effect on the blood biochemical parameters of turkeys, but it supports an increase in their final body weights and a significant increase in n-3 PUFA concentrations in meat lipids.

\section{REFERENCES}

AOAC, 2005. Association of Official Analytical Chemists, Official Methods of Analysis. $18^{\text {th }}$ Edition. Arlington, VA

Aviagen Inc., 2007. Management essentials for commercial turkeys.http://en.aviagen.com/

Crespo N., Esteve-Garcia E., 2002. Dietary linseed oil produced lower abdominal fat deposition but higher de novo fatty acid synthesis in broiler chickens. Poultry Sci. 81, 1555-1562

Delezie E., Aerts J.M., Maertens L., Huyghebaert G., 2010. The efficiency of long chain n-3 fatty acid deposition of different dietary oils in turkeys at different ages. Arch. Geflügelk. 74, 51-57

Febel H., Mezes M., Palfy T., Herman A., Gundel J., Lugsi A., Balogh K., Kocsis I., Blazovics A., 2008. Effect of dietary acid pattern on growth, body fat composition and antioxidant parameters in broilers. J. Anim. Physiol. Anim. Nutr. 92, 369-376

Harris W.S., Poston W.C., Haddock C.K., 2007. Tissue n-3 and n-6 fatty acids and risk for coronary heart disease events. Atherosclerosis 193, 1-10

Has-Schön E., Skrtic Z., Kralik G., 2008. Beneficial effects of different dietary oils on cholesterol level and fatty acids profile of turkey pectoral muscle. Ital. J. Anim. Sci. 7, 161-171

Jia W., Rogiewicz A., Bruce H.L., Slominski B.A., 2010. Feeding flaxseed enhances deposition of omega-3 fatty acid in broiler meat portions in different manner. Can. J. Anim. Sci. 90, 203-206

Jurgonski A., Juskiewicz J., Zdunczyk Z., 2008. Ingestion of black chokeberry fruit extract leads to intestinal and systemic changes in a rat model of prediabetes and hyperlipidemia. Plant Food. Hum. Nutr. 63, 176-182

Kavouridou K., Barroeta A.C., Villaverde C., Manzanilla E.G., Baucells M.D., 2008. Fatty acid, protein and energy gain of broilers fed different dietary vegetable oils. Spanish J. Agr. Res. 6, 210-218

Lopez-Ferrer S., Baucells M.D., Barroeta A.C., Grashorn M.A., 1999. n-3 enrichment of chicken meat using oil: alternative substitution with rapeseed and linseed oils. Poultry Sci. 78, 356565

Mikulski D., Jankowski J., Zduńczyk Z., Wróblewska M., Sartowska K., Majewska T., 2009. The effect of selenium source on performance, carcass traits, oxidative status of the organism, and meat quality of turkeys. J. Anim. Feed Sci. 18, 318-330

Mossab A., Hallouis J.M., Lessire M., 2000. Utilization of soybean oil and tallow in young turkeys compared with young chickens. Poultry Sci. 79, 1326-1331

Nguyen C.V., Smulikowska S., Mieczkowska A., 2003. Effect of linseed and rapeseed or linseed and rapeseed oil on performance, slaughter yield and fatty acid deposition in edible parts of the carcass in broiler chickens. J. Anim. Feed Sci. 12, 271-288

Peisker K., 1964. A rapid semi-micro method for preparation of methyl esters from triglycerides using chloroform, methanol, sulphuric acid. J. Amer. Oil Chem. Soc. 11, 87-90

Rahimi S., Kamran Azad S., Karimi Torshizi M.A., 2011. Omega-3 enrichment of broiler meat by using two oil seeds. Agr. Sci. Tech. 13, 353-365 


\section{6}

VEGETABLE OILS - PERFORMANCE AND FA PROFILE IN TURKEYS

Ravindran V., Hew L.I., Ravindran G., Bryden W.L., 1999. A comparison of ileal digesta and excreta analysis for the determination of amino acid digestibility in food ingredients for poultry. Brit. Poultry Sci. 40, 266-274

StatSoft Inc., 2007. Statistica (data analysis software system), Version 8.0 www.statsoft.com.

Weill P., Schmitt B., Chesneau G., Daniel N., Safraou F., Legrand P., 2002. Effect of introducing linseed in livestock diet on blood fatty acid composition of consumers of animal products. Ann. Nutr. Metab. 46, 182-191

Zanini S.F., Colnago G.L., Bastos M.R., Pessotti B.M.S., Casagrande F.P., Lima V.R., 2006. Oxidative stability and total lipids on thigh and breast meat of broiler fed diets with two fat sources and supplemented with conjugated linoleic acid. Food Sci. Technol. Int. 39, 717-723 